\title{
Alcohol Consumption and Its Effect on Testicular Structure and on Sperm Count and Motility in Parent Mice and Their Offspring
}

\author{
Albadri CTa, Al Ani IMph, Hiba HMAc \\ a Department of Biology, Faculty of Science, Sana'a University, Sana'a, Yemen. \\ ${ }^{b}$ Department of Basic Medical Science, Kulliyyah of Medicine, International Islamic University, Kuantan, \\ Malaysia. \\ ' Department of Biological Science, Faculty Of Science, King Abdul-Aziz University, P.O. Box 8023 Jeddah, \\ KSA
}

\begin{abstract}
Introduction: The goal of the present study was to examine the effect of alcohol consumption on sperm count and motility and the morphological changes in the seminiferous tubules of parent mice and their offspring. Methods: Animals were divided into two groups, Group 1 (alcohol group) of twelve male and twelve female mice, were given a daily dose of ( $3 \mathrm{~g} / \mathrm{kg}$ body weight as $25 \%, \mathrm{v} / \mathrm{v})$ ethanol by gastric gavage for four and eight weeks. Group 2 (control group) also of twelve male and twelve female mice; received normal access of food and water. After four weeks of treatment, the males and females in each group were allowed to mate, and ethanol treatment continued for up to another four weeks. Twelve male offspring from group 1 and twelve male offspring from group 2 were selected randomly and allowed to become mature. Male parent mice were killed at the $4^{\text {th }}$ and $8^{\text {th }}$ weeks of treatment, and their male offsprings were killed when they reached maturity age. Results: Physiological examination of the sperm solution showed that there was a significant decrease in sperm count and motility after 4 and 8 weeks of ethanol treatment in parent male mice, but this decrease was not significant in their adult offspring. Furthermore, histological investigations indicated testicular lesions in the parent male mice and their adult male offspring. Conclusion: Alcohol abuse has deleterious effects on the testes structure and on the sperm count and motility of the epididymal spermatozoa of both parent mice and their offspring.
\end{abstract}

KEYWORDS: Alcohol, offspring, tests, sperm count, sperm motility.

\section{INTRODUCTION}

Alcohol consumption by humans dates back to the very early part of man's history; many archaeologists believe that wines made from grapes have existed for more than 10,000 years and have existed for even longer; it has religious and ethical challenges as well as psychological and behavioural impacts. Alcohol is a powerful, addictive and central nervous system depressant; alcohol abuse or dependence led to increased risk of major depression. ${ }^{1}$ Chronic alcohol consumption has a widespread impact on the central nervous system; it induces oxidative stress, and impairs cerebral vasoreactivity, and thus may result in an increase in ischemic stroke-induce brain damage. ${ }^{2}$

Corresponding author:

Cinaria T. Albadri

Department of Biology,

Faculty of Science,

Sana'a University,

Sana'a, Yemen.

Phone: 00353868842071

E-mail:cinariaalbadri@yahoo.com
A strong positive relationship has been found between alcohol consumption and risk of mortality from stroke. ${ }^{3}$

There is an increasing body of evidence suggesting harm to the fetus from alcohol consumption during pregnancy; Alcohol may exert toxic effects during the reproductive process from infertility through miscarriage, aneuploidy, structural congenital anomaly, disordered fetal growth, perinatal death, developmental delay and indeed susceptibility to disease in adult life. ${ }^{4}$ Recently, researchers have become very interested in the effects of alcohol on the reproductive system. The most important endocrine consequences of long term alcohol use are its effects on the gonads. In human, high alcohol consumption is associated with serious disorders of spermatogenesis. ${ }^{5}$ Male alcoholics report problems such as erectile dysfunction and lowered fertility, effects that have been explained by an alcohol-induced reduction in testosterone. ${ }^{6}$ Gonadal dysfunction that occurs in man as a consequence of chronic ethanol ingestion confirms the data which suggest that ethanol is a primary testicular toxin. ${ }^{7}$ Alcohol abuse in men can cause impaired testosterone production and testicular atrophy; these changes can result in impotence, infertility, and reduced male secondary sexual 
characteristics. ${ }^{8}$ Apoptosis is significantly induced in ethanol treated animals indicating the tissue injury of testicles; injections of ethanol solution in rats enhanced testicular DNA fragmentation, and increased the number of apoptotic spermatogonia as well as spermatocytes..$^{9,10}$ Alcohol also causes an adverse effect on the secretory function of Sertoli cells. ${ }^{11}$ Despite the numerous studies on the effect of alcohol on male reproduction, but its exact effect on sperm parameters has not been well investigated yet. No evidence has so far been documented about the effects of alcohol consumption during gestation on the offspring sperm parameters. Aim of the present study is to observe the main physiological features of sperm in parent mice and in their offspring that may be caused by chronic alcohol consumption.

\section{MATERIALS \& METHODS}

\section{Animals}

Forty eight parent mice of the BALB/C strain (twenty four virgin female and twenty four male) weighing $25-30 \mathrm{~g}$ and aged 6-8 weeks, were used in this study. Twenty four male mice from the parent offspring were also selected and used in the second part of the experiment. The mice were kept under suitable environmental conditions such as a room temperature that was maintained at $(20-24)^{\circ} \mathrm{C}$ and exposed to 12 hour/day light program. They received pellets and were allowed for free access of water ad libitum.

\section{Experimental design}

The animals were divided into two groups. Group 1 was the control group of twelve male and twelve virgin female. Group 2 was the alcohol group, also of twelve male and twelve virgin female. The alcohol group were administered daily with oral doses of $(3 \mathrm{~g} / \mathrm{kg}$ body weight as $25 \% \mathrm{v} / \mathrm{v}$ ) ethanol using a gastric tube, ${ }^{12}$ for four and eight weeks respectively. Male animals were kept in separate cages from the virgin females. After four weeks of treatment, twelve males and twelve females were killed and the remaining twelve males and twelve females were allowed to mate. Alcohol treatment continued to males for another four weeks and for the females following diagnosis of pregnancy until the delivery of their offspring, up to another four weeks. After delivery, alcohol treatment was stopped. The offsprings were weaned at 21 days of age and were allowed to reach maturity age. Parent mice were sacrificed at the $4^{\text {th }}$ and $8^{\text {th }}$ weeks of treatment. Male offsprings (of twelve mice each) were selected from group 1 and group 2 and killed at a maturity age (eight weeks), testes were taken from parents after $8^{\text {th }}$ weeks of treatment and from their adult offsprings, fixed with Bouin's solution for 24 hours, dehydrated by series of ethanol, cleared in xylene and embedded in paraffin wax. Paraffin sections of $5 \mu \mathrm{m}$ thickness were stained with haematoxylin and eosin.

\section{Estimation of sperm count and sperm motility}

Immediately after killing the animals, the caudal epididymis part of each animal was removed and placed in a small clean Petri dish containing $1 \mathrm{ml}$ of Phosphate Buffer Saline $\mathrm{pH}=7.4$. The caudal part was cut by a sharp sterilized blade into three pieces and squeezed gently by a fine forceps to release the sperm into the phosphate buffer saline, and the suspension wasthenallowed to settleat $37^{\circ} \mathrm{C}$ for $10 \mathrm{~min} .{ }^{13}$ Sperm were counted using a Neubaur Hemocytometer Chamber. Sperm suspension was placed on both sides of the Chamber and the number of sperm in the appropriate squares of the Chamber was counted under the microscope at 100X magnification. ${ }^{14}$ Sperm count and motility was performed four times for each sample. ${ }^{15}$

\section{Statistical analysis}

Statistical analysis was performed using SPSS Statistical Program. The differences in means of sperm counts and sperm motility between the tests and control were compared using Student's t-test and paired samples $t$-test. The results were expressed as mean \pm standard deviation.

\section{RESULTS}

Light microscopy examination of the testes of the control mice (parent and their offspring) showed normal structural features of seminiferous tubules and interstitial tissues (Figure 1). The Sertoli cells, and the spermatogenic cells (namely, the spermatogonia, primary and secondary spermatocytes; spermatoids and spermatozoa) resting on the thin basal lamina. 


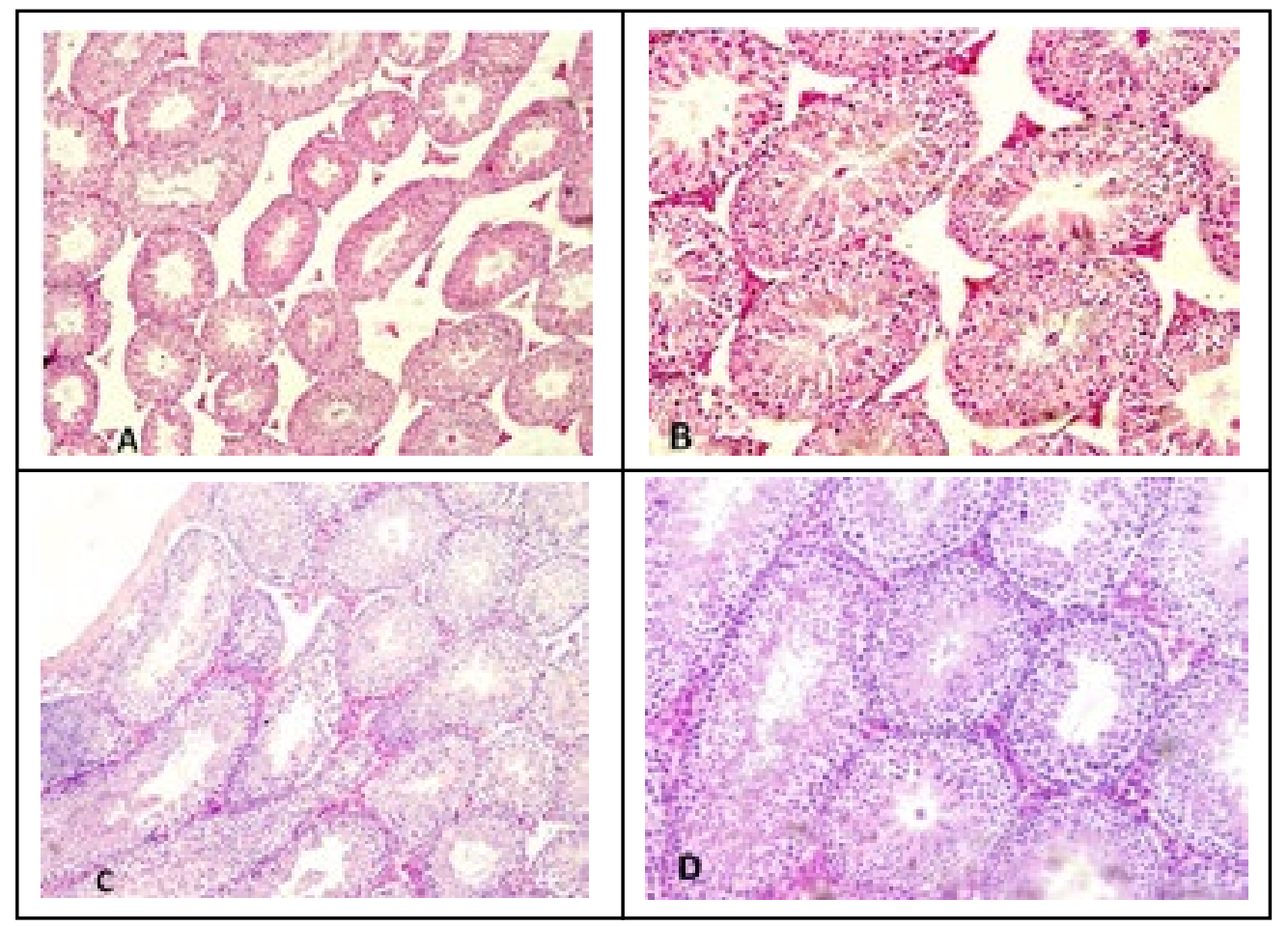

Figure 1: Testes of the control parent group (A, B) and of their offspring $(C, D)$ showing regular seminiferous tubules with normal germinal epithelium morphology. (H\&E, original magnification, "A\&C" X 10; "B\&D" X20).

After eight weeks of alcohol treatment, parent mice revealed cellular changes in the seminiferous tubules. The affected tubules exhibited thickness in the basement membrane. Some seminiferous tubules were destructed by necrotic cells. Degenerative changes were observed in the spermatogenic epithelium and Sertoli cells. Clusters of degenerating spermatozoa and desquamated spermatogenic cells were frequently observed deep within the lumina of the seminiferous tubules. Interstitial tissues showed congested blood vessels and mononuclear infiltration (Figure $2, A \& B$ ). The offspring's testis also showed degenerative changes; there were visible lesions and degeneration of the some seminiferous tubule epithelium, abnormal distribution of spermatozoa showed in the lumina of the seminiferous tubules. Interstitial tissues showed congested blood vessels and mononuclear infiltration (Figure 2, C\& D).

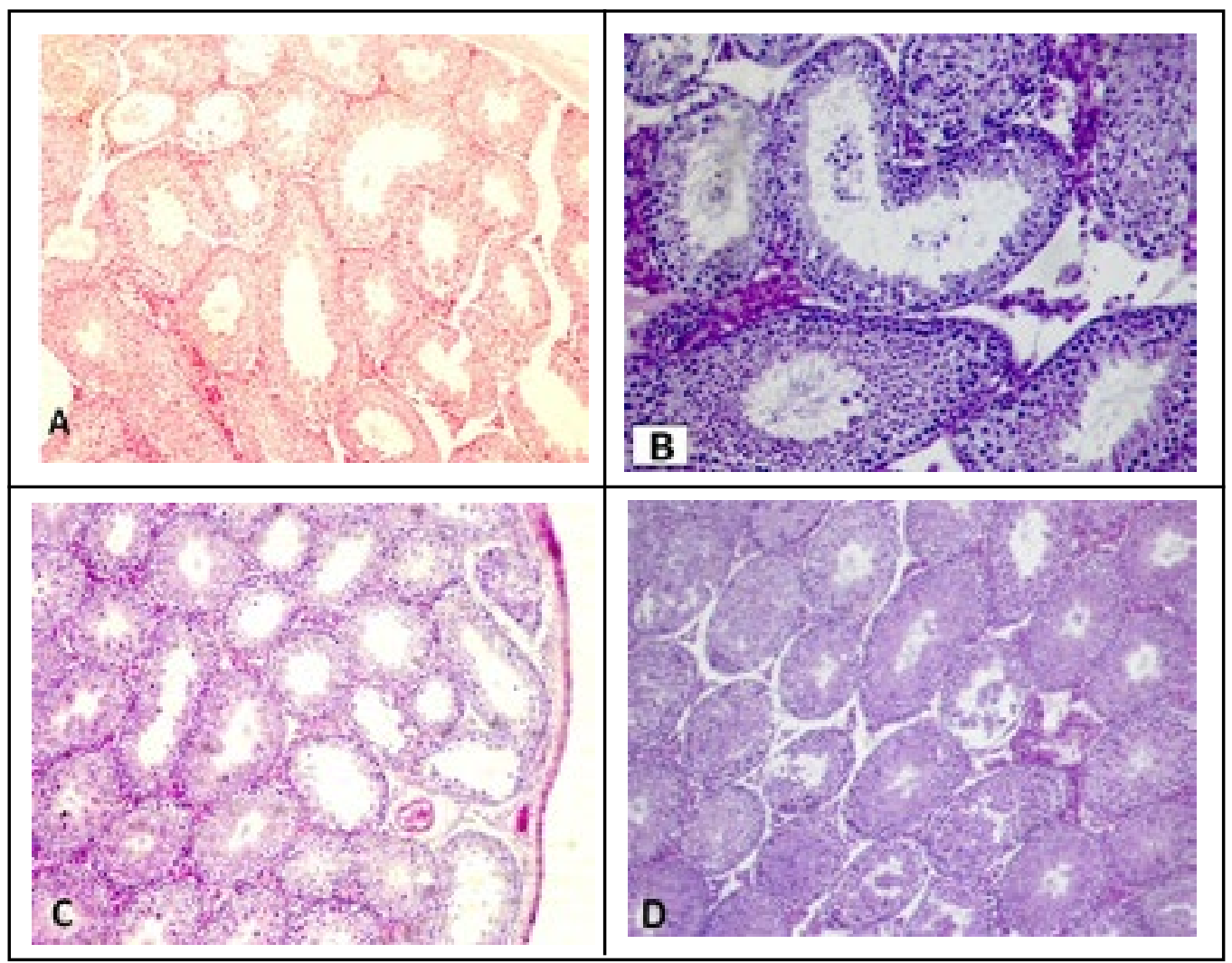

Figure 2: Testes of the ethanol treated group (A, B) after eight weeks of treatment and of their offspring (C, D) showing destruction of the seminiferous tubules, congested blood vessels and mononuclear infiltration. (H\&E, original magnification, “A, C\&D” X 10; "B" X20). 
Alcohol treatment showed a significant decline $(P<0.05)$ in the parental spermatozoa number $(38.33 \pm 5.35 \mathrm{x}$ $\left.10^{6} / \mathrm{ml}\right)$ at the $4^{\text {th }}$ weeks compared to their control mice $\left(76.33 \pm 9.03 \times 10^{6} / \mathrm{ml}\right)$ and $\left(31.67 \pm 5.29 \times 10^{6} /\right.$ $\mathrm{ml})$ at the 8th weeks compared to their control mice $\left(70.33 \pm 9.41 \times 10^{6} / \mathrm{ml}\right)$. The offspring of the parent alcohol treated mice showed a non significant decline $(P>0.05)$ of the spermatozoa number $(15.83 \pm 17.5 \times$ $\left.10^{6} / \mathrm{ml}\right)$ compared to their control $\left(67.33 \pm 10.54 \times 10^{6} /\right.$ $\mathrm{ml}$ ) (Table 1). A significant decline $(\mathrm{P}<0.05)$ in sperm motility of the parent mice $(18 \pm 1.41 \%)$ compared to control mice $(52.5 \pm 4.04 \%)$ was shown at the $4^{\text {th }}$ weeks and $(15 \pm 3.69 \%)$ at the $8^{\text {th }}$ weeks compared to their control mice $(46.67 \pm 6.71 \%)$. The offspring of the parent treated mice also showed a non significant decline $(P>0.05)$ of motile spermatozoa $(14.67 \pm 14.23 \%)$ compared to their control $(48.33 \pm 7.26 \%)$ (Table 1).

Table 1. Average of sperm count and sperm motility of parent mice treated with ethanol and their offspring expressed as (Mean $\pm \mathrm{Sd}$ ).

\begin{tabular}{|c|c|c|c|c|c|c|}
\hline & \multicolumn{4}{|c|}{ Parent Mice } & \multicolumn{2}{|c|}{ Offspring Mice } \\
\hline & $\begin{array}{c}C 1 \\
(n=12) \\
(\text { Mean } \pm S d) .\end{array}$ & $\begin{array}{c}E 1 \\
(n=12) \\
(M e a n \pm S d)\end{array}$ & $\begin{array}{c}C 2 \\
(n=12) \\
(\text { Mean } \pm S d) .\end{array}$ & $\begin{array}{c}\text { E2 } \\
(n=12) \\
(M e a n \pm S d) .\end{array}$ & $\begin{array}{c}C 3 \\
(n=12) \\
(\text { Mean } \pm S d) .\end{array}$ & $\begin{array}{c}E 3 \\
(n=12) \\
(\text { Mean } \pm S d) .\end{array}$ \\
\hline $\begin{array}{l}\text { Sperm } \\
\text { count } \\
\left(10^{6} / \mathrm{ml}\right)\end{array}$ & $\begin{array}{l}76.33 \\
\pm 9.03\end{array}$ & $\begin{array}{l}38.33 \\
\pm 5.35^{*}\end{array}$ & $\begin{array}{l}70.33 \\
\pm 9.41\end{array}$ & $\begin{array}{l}31.67 \\
\pm 5.29^{*}\end{array}$ & $\begin{array}{r}67.33 \\
\pm 10.54\end{array}$ & $\begin{array}{c}15.83 \\
\pm 17.5 \#\end{array}$ \\
\hline $\begin{array}{l}\text { Sperm } \\
\text { motility } \\
\text { (\%) }\end{array}$ & $\begin{array}{c}52.5 \\
\pm 4.04\end{array}$ & $\begin{array}{c}18 \\
\pm 1.41^{*}\end{array}$ & $\begin{array}{l}46.67 \\
\pm 6.71\end{array}$ & $\begin{array}{c}15 \\
\pm 3.69^{*}\end{array}$ & $\begin{array}{r}48.33 \\
\pm 7.26\end{array}$ & $\begin{array}{c}14.67 \\
\pm 14.23 \#\end{array}$ \\
\hline
\end{tabular}

* Significant $(\mathrm{P}<0.05)$ to their control.

\# Not Significant $(P>0.05)$ to their control.

C1: control group (Parent mice allowed for free food for 4 weeks).

E1: ethanol group (Parent mice treated with ethanol for 4 weeks).

C2: control group (Parent mice allowed for free food for 8 weeks).

E2: ethanol group (Parent mice treated with ethanol for 8 weeks).

C3: control group (offspring of parent mice allowed for free food).

E3: ethanol group (offspring of parent mice treated with ethanol).

\section{DISCUSSION}

Alcohol abuse is considered as one of the problems associated with poor semen production and sperm quality. The consumption of alcohol offers no benefits in relation to the outcomes of pregnancy, and alcohol is both teratogenic and fetotoxic in the human. ${ }^{4}$ Numerous studies have indicated that alcohol abuse in men can cause impaired testosterone production and testicular atrophy. ${ }^{8}$ Testicular atrophy results primarily from the loss of sperm cells and decreased diameter of the seminiferous tubules. The present study showed destruction of the seminiferous tubules and pronounced changes in the epithelium of the tubules when animals were ingested with alcohol for eight weeks. This is in consistent with previous studies that showed that ethanol injection in mice revealed degenerative changes of epithelial component of the seminiferous tubules, ${ }^{16}$ and alcohol-treated rats presented testicular lesions including a significant decrease in the diameter of the seminiferous tubules, decrease of Leydig cell's number and the presence of degenerative germ cells. ${ }^{17}$ There was histological evidence of testicular lesions and incomplete progression of spermatogenesis in pigs fed ethanol with many basal vacuoles and great reduction in sperm density. ${ }^{18}$

In this study, the results of the effect of alcohol on both sperm count and motility have shown a decrease in parent mice and their offspring; indicating that long term alcohol consumption for eight weeks or more "in mice" causes a decline in sperm count and motility of their offspring and providing evidence that addiction to alcohol will cause testicular lesions and reduced activity of spermatozoa in the offspring; this is in agreement with a number of clinical and experimental studies that observed impaired spermatogenesis (reduces sperm content) under chronic ethanol consumption. ${ }^{12,19,20}$ Anderson et al. ${ }^{21}$ also observed low sperm content in the caudal epididymis of ethanol (5\% for 20 weeks and $6 \%$ for five weeks) consumed rats. The testis has been shown to be highly susceptible to ethanol as it crosses the blood testes barriers. ${ }^{22}$ 
The mechanism by which alcohol consumption by the parents during pregnancy that resulted in tubular atrophy and retarded spermatogenesis in the offsprings was not established from the result of this study. However, alcohol has neurotoxin activity and could destroy the developing neurons, including that of the hypothalamus. ${ }^{23}$ Ethanol has been shown to induce nervous system damage, including long-term reduced neurogenesis in the hippocampus, ${ }^{24}$ widespread brain atrophy, ${ }^{25}$ and induced inflammation in the brain. ${ }^{26}$ Alcohol can interfere with the function of the hypothalamic-pituitary-gonadal (HPG) axis; thereby causing impotence, infertility, and reduced male secondary sexual characteristics. ${ }^{27}$ Chronic ethanol administration resulted in high oxidative stress in the testes either due to the increased extent of lipid peroxidation or due to decreased antioxidant defenses, and thereby induces germ cell apoptosis leading to testicular atrophy. ${ }^{20}$

The present study has demonstrated a reduction of sperm count and motility after 4 and 8 weeks of ethanol treatment in parent mice, and their adult offspring. After spermatozoa leave the testes in an immature state, they undergo further maturation and acquire the potential for progressive motility during passage through the caput and corpus epididymides. ${ }^{28}$ Epididymal secretory products furnish a microenvironment that is considered vital for acquisition of motility and viability of sperm, carnitine and acetyl carnitine are epididymal secretory products, which play an important role in spermatozoa maturation. ${ }^{12}$ In contrast, Srikanth et al. ${ }^{12}$ showed that Cauda epididymal sperm motility, and the fertility of ethanol-treated rats were significantly impaired compared to control rats and suggested that these changes are likely to be the consequence of direct and indirect effects of ethanol mediated through subnormal testosterone and dihydrotestosterone; they also suggested that the impaired activity of sperm glycosidases may be one of the factors responsible for defective sperm motility and fertilizing potential in ethanol-treated rats. A significant decrease in epididymal sperm motility associated with significant low levels of serum testosterone, luteinizing hormone (LH), and follicle stimulating hormone (FSH) were observed in the ethanol-treated mice. ${ }^{29}$ Ethanol consumption disturbs cauda epididymal spermatozoa motility, nuclear maturity and DNA integrity of spermatozoa in rat; and this may be one possible cause of infertility following ethanol consumption. ${ }^{30}$

The low sperm count of ethanol-treated mice in this study may be attributed to the effect of alcohol on the gonadotrophic cells of the pituitary gland and/or directly on the seminiferous tubules and Leydig cells, in addition the neurotoxin activity of ethanol may have destroyed the developing neurons of the offspring. Further studies are needed to investigate the serum total testosterone, luteinizing hormone (LH) and follicle-stimulating hormone (FSH) concentrations in the offspring of alcohol treated parents.

\section{CONCLUSION}

The present study demonstrates the deleterious effects of alcohol consumption on the testes structure and on the sperm count and motility of the epididymal spermatozoa of both parent mice and their offspring.

\section{RECOMMENDATION}

It is recommended that, women who are pregnant (or considering a pregnancy) should not drink alcoholic beverages and alcohol-containing products.

\section{ACKNOWLEDGEMENT}

We are thankful to Mr. Ammar Essam Al-Hily, Department of Biology, College of Science; Sana'a University for his technical assistance during the practical work of this study.

\section{REFERENCES}

1. Fergusson DM, Boden JM, Horwood LJ. Tests of casual links between alcohol abuse or dependence and major depression. Arch Gen Psychiatry 2009; 66:260-6.

2. Sun H, Zhao H, Sharpe GM, Arrick DM, Mayhan WG. Effect of chronic alcohol consumption on brain damage following transient focal ischemia. Brain Res 2008; 1194:73-80.

3. Hart CL, Smith GD, Hole DJ, Hawthorne VM. Alcohol consumption and mortality from all causes, coronary heart disease, and stroke: results from a prospective cohort study of Scottish men with 21 years of follow up. BMJ 1999; 318:1725-9.

4. Fraser RB. Alcohol Consumption and the Outcomes of Pregnancy. RCOG Statement 2006; No 5:1-10.

5. Pajarinen J, Karhunen PJ, Savolainen V, et al. Moderate Alcohol Consumption and Disorders of Human Spermatogenesis. Alcohol Clin Exp Res 1996; 20:332-7.

6. Bannister P, Lowosky M. Ethanol and hypogonadism. Alcohol 1987; 73:86-93.

7. Van Thiel DH, Gavaler JS, Lester R, Goodman $M D$. Alcohol induced testicular atrophy: an experimental model for hypogonadism occurring in chronic alcoholic men. Gastroenterology 1975; 69:326-32.

8. Adler RA. Clinically important effects of alcohol on endocrine function. J Clin Endocrinol Metabol 1992; 74:957-60.

9. Zhu Q, Meisinger J, Emanuelle NV, et al. Ethanol exposure enhances apoptosis within the testes. Alcohol Clin Exp Res 2000; 24:1550-6.

10. Bamac Y, Colak T, Bamac B, et al. Comparative study on apoptosis in the testes of normal and alcoholic rats. Saudi Med J 2005;26:928-33. 
11. Zhu Q, Van Thiel DH, Gavaler JS. Effects of ethanol on rat Sertoli cell function: studies in vitro and in vivo. Alcohol Clin Exp Res 1997; 21:1409-17.

12. Srikanth V, Malini T, Arunakaran J, Govindarajulu P, Balasubramanian K. Effects of ethanol treatment on epididymal secretory products and sperm maturation in albino rats. J Pharmacol Exp Ther 1999; 288:509-15.

13. Anjamrooz SH, Movahedin M, Mowla SJ, Bairanvand SP.Assessment of morphological and functional changes in the mouse testis and epididymal sperms following busulfan treatment. Iranian Biomed J 2007; 11:15-22.

14. Zaneveld LJ, Polakosk KL. Collection and physical examination of the ejaculate in techniques of human andrology. Ed. Hafez ESE. North Holland Biomedical Press, Amsterdam.1977; 147-56.

15. Cheng Y, Buffone MG, Kouadio M, et al. Abnormal sperm in mice lacking the Taf7L gene. Mol Cell Biol 2007; 27:2582-9.

16. $\mathrm{Hu} \mathrm{JH}$, Jiang J, Ma YH, et al. Enhancement of germ cell apoptosis induced by ethanol in transgenic mice over expressing Fas Ligand. Cell Res 2003; 13:361-7.

17. El-Sokkary GH. Quantitative study on the effects of chronic ethanol administration on the testis of adult male rat. Neuro Endocrinol Lett 2001; 22:93-9.

18. Wallock-Montelius LM, Villanueva JA, Chapin $\mathrm{RE}$, et al. Chronic ethanol perturbs testicular folate metabolism and dietary folate deficiency reduces sex hormone levels in the Yucatan micropig. Biol Reprod 2007; 76:455-65.

19. Haider SG, Hoffmann N, Passia D. Morphological and enzyme histochemical observations on alcohol-induced disturbances in testis of two patients. Andrologia 1985; 17: 532-40.

20. Ganaraja B, Crystal D, Vijayalakshmi BM, et al. Use of vitamin $C$ on effect of ethanol induced lipid peroxidation in various tissues, sperm count and morphology in the Wistar rats. J Chinese Clin Med 2008, 3:1-5.

21. Anderson RA Jr, Willis BR, Oswald C, Zaneveld LJ. Ethanol-induced male infertility: Impairment of spermatozoa. J Pharmacol Exp Ther 1983; 225:479-86.

22. Maneesh M, Jayalekshmi H, Dutta S, Chakrabarti A, Vasudevan DM. Role of oxidative stress in ethanol induced germ cell apoptosis an experimental study in rat. Indian J Clin Bioch 2005; 20:62-67.

23. Leonard EB. Ethanol as a neurotoxin. Biochem Pharmacol 1989; 36:2005-59.

24. Taffe MA, Kotzebue RW, Crean RD, et al. Long-lasting reduction in hippocampal neurogenesis by alcohol consumption in adolescent nonhuman primates. Proc Natl
Acad Sci USA 2010; 107:11104-9.

25. Bleich S, Bandelow B, Javaheripour K, et al. Hyperhomocysteinemia as a new risk factor for brain shrinkage in patients with alcoholism. Neurosci Lett 2003; 335:179-82.

26. Blanco AM, Vallés SL, Pascual M, Guerri C. Involvement of TLR4/type I IL-1 receptor signaling in the induction of inflammatory mediators and cell death induced by ethanol in cultured astrocytes. J Immunol 2005; 175:6893-9.

27. Emanuele MA, Emanuele NV. Alcohol's effects on male reproduction. Alcohol Health Res World 1998; 22:195-201.

28. Bedford JM. Maturation, transport and fate of spermatozoa in the epididymis. Handbook of physiology. Eds. Hamilton DW and Greep RO, section 7, Endocrinology 5, Male Reproductive System. Am Physiol Soc, Washington DC, 1975.

29. Jang M, Min JW, In JG, Yang DC. Effects of red ginseng extract on the epididymal sperm motility of mice exposed to ethanol. Int J Toxicol 2011; 30:435-42.

30. Talebi AR, Sarcheshmeh AA, Khalili MA, Tabibnejad N. Effects of ethanol consumption on chromatin condensation and DNA integrity of epididymal spermatozoa in rat. Alcohol 2011; 45:403-9. 